\title{
SWIMMING ABILITY OF NOTONECTIDAE (HEMIPTERA)
}

\author{
By STEVEN H. GiTTELMAN* \\ Biological Sciences Group, University of Connecticut \\ Storrs, Conn. 06268
}

In an earlier paper, I (Gittelman 1974) studied adaptations of fore-leg size and hind-leg lever systems for prey capture and swimming. Presently, the ability of 4 species of Connecticut Notonecta to swim against a current is studied as a test of predictions generated by this earlier work.

To study leg mechanics we will schematically represent a leg or leg segment (femur, tibia, and tarsus) as a simple lever with the fulcrum at the articulation between it and the structure on which it articulates. Force $\left(F_{m}\right)$ is applied at the muscle insertions at the proximal end and the lever arm is the distance $\left(R_{1}\right)$ from the fulcrum to where the force is applied, the resultant force $\left(F_{\mathrm{r}}\right)$ is the force generated by the lever to do work (press against water while swimming) at any given distance $\left(R_{2}\right)$ away from the fulcrum and is related to the muscular force as follows:

$$
F_{r}=\frac{R_{1}}{R_{2}} F_{m}
$$

The ratio $R_{1} / R_{2}$ corresponds to the mechanical advantage. Smith and Savage (1956) compared the mechanical advantage of muscles of the forelegs of the horse (Equus) and a fossorial armadillo (Dasypus). They concluded that if the $R_{1} / R_{2}$ ratio is large, leg movement will be powerful though slow. If the ratio is small, it will be fast but weak.

Gittelman (1974) measured $R_{1} / R_{2}$ ratios in 10 species of North American Notonectidae in the genera Notonecta (4 spp.), Buenoa (4 spp.) and Martarega (2 spp.). The total length of the hind-leg $\left(\mathrm{R}_{2}\right)$ from the trochanter-coxa articulation to the distal tip of the tarsi (not including the tarsal claw), and the lever arm $\left(R_{1}\right)$, the distance from the ventral trochanter-coxa articulation to the proximal end of the trochanter at the insertion of the depres-

*Present address: Box 229, Jericho, N.Y., 11753.

Manuscript received by the editor October 30, 1976. 
sor muscle tendon, were measured for each species of backswimmer studied. As an example of these measurements a ventral view of the proximal leg segments of the metathoracic leg of Notonecta undulata is included in Figure 1. In this earlier study, the mechanical advantage differed among species of different genera, with Martarega having the lowest and Buenoa the highest $R_{1} / R_{2}$ ratios. It was concluded that the low mechanical advantage of the former is an adaptation to living in a current. These backswimmers live in rivers and swim slowly against the water flow, maintaining their position, while feeding on immobile prey trapped in the water surface. The larger mechanical advantages found in Buenoa seem associated with a diet of highly mobile prey requiring the predator to accelerate rapidly in pursuit. It was concluded that the intermediate mechanical advantage exhibited by Notonecta represents an ecological compromise between Buenoa and Martarega. Buenoa, which swim below the water surface, prey almost exclusively on free-moving prey. Notonecta spend much of their time at the water surface and probably eat

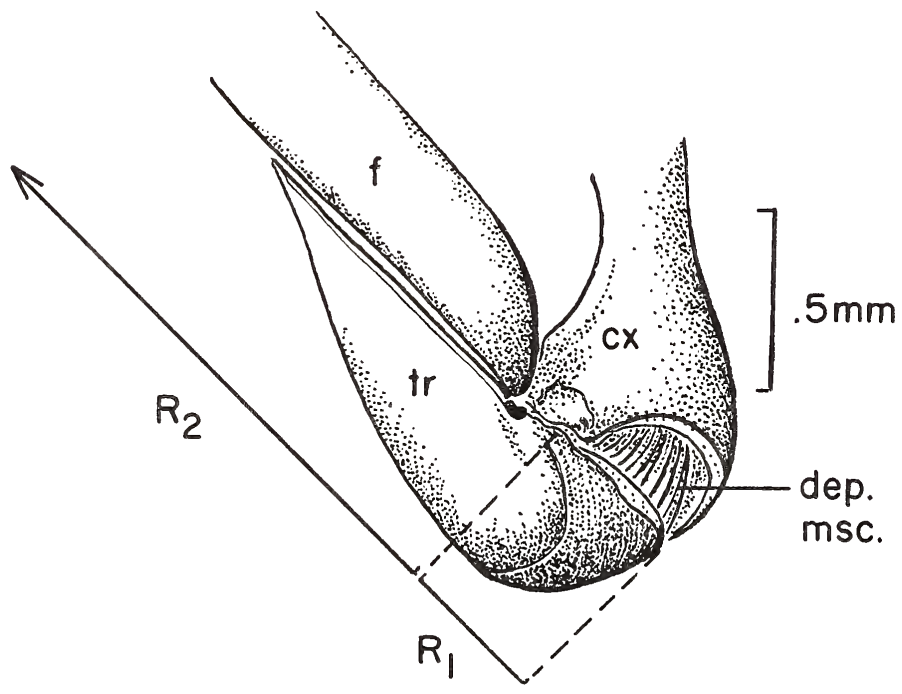

Fig. 1. Ventral view of the proximal leg segments of the right metathoracic leg of Notonecta undulata. tr, trochanter; cx, coxa; f, femur; dep. msc., depressor muscle; $R_{1}$, the lever arm; $R_{2}$, the lever (see text for explanation). 
a greater proportion of prey stranded on the water film than do Buenoa, but less so than Martarega. However, since Buenoa and Notonecta are found in static water, one expects them to be more similar to each other than either is to Martarega, which is the case.

Significant differences between mechanical advantages of Notonecta spp. were found to exist. In the present Table 1 these $R_{1} / R_{2}$ coefficients are reproduced. The $R_{1} / R_{2}$ coefficient of insulata, the largest backswimmer, is smallest of the species studied. The coefficient of lunata is smaller than that of undulata and irrorata, but the latter two are not significantly different from each other. The magnitude of $R_{1} / R_{2}$ appears to increase with body size in all but insulata.

If as I proposed earlier (Gittelman 1974), low values of mechanical advantage are adaptations for low acceleration swimming (e.g. continual swimming against a current), then of these 4 species of Notonecta, insulata should be best able to swim against a current. The following is a test of this prediction.

Table 1. Measurements ${ }^{\#}$ (in $\mathrm{mm}$ ), $\mathrm{R}_{1} / \mathrm{R}_{2}$ coefficients ${ }^{\#}$ and the maximum water current where position could be maintained of 4 species of Notonecta (Notonectidae). Current speeds with different letters are significantly different at the $\mathrm{P}<0.01$ level (2-tailed $\mathrm{t}$-test). $\overline{\mathrm{x}}$, mean; $\mathrm{s}$, standard deviation.

\begin{tabular}{|c|c|c|c|c|c|c|}
\hline \multirow[b]{2}{*}{ Species } & \multirow[b]{2}{*}{$\begin{array}{l}\text { Body } \\
\text { length }\end{array}$} & \multirow[b]{2}{*}{$\begin{array}{c}\mathrm{R}_{2} \\
\text { (leg length) }\end{array}$} & \multirow[b]{2}{*}{$\begin{array}{c}\mathrm{R}_{1} \\
\text { (lever arm) }\end{array}$} & \multirow[b]{2}{*}{$\mathrm{R}_{1} / \mathrm{R}_{2}$} & \multicolumn{2}{|c|}{$\begin{array}{l}\text { Water current } \\
(\mathrm{cm} / \mathrm{sec})\end{array}$} \\
\hline & & & & & $\overline{\mathrm{x}}$ & $\mathrm{s}$ \\
\hline N. insulata & 14.50 & 14.93 & 0.458 & $0.031^{*}$ & $8.74^{\mathrm{a}}$ & 2.39 \\
\hline N. lunata & 9.78 & 9.83 & 0.317 & $0.032 *$ & $4.15^{b}$ & 1.57 \\
\hline N. undulata & 11.87 & 11.63 & 0.390 & 0.034 & $6.21^{\mathrm{c}}$ & 2.26 \\
\hline N. irrorata & 13.83 & 13.14 & 0.471 & 0.036 & $4.19^{b}$ & 1.58 \\
\hline
\end{tabular}




\section{METHODS}

The apparatus consisted of a plexiglass trough $(7 \times 32 \mathrm{~cm})$ within which was placed a second, "U" shaped trough with screen baffles on each end. Water was fed into the inner trough by means of a $2.4 \mathrm{~cm}$ hose coming from a 201 reservoir positioned $35 \mathrm{~cm}$ above the trough. A hose from a second distilled water source kept the reservoir filled and an overflow kept the water level constant. In this way water within the hose entering the trough was maintained at a constant pressure. A clamp between the reservoir and the trough regulated the current flow. Water flow within the confined area of the U-shaped inner trough appeared to be uniform when checked with methylene blue dye. Current velocity was measured with a Gurley No. 625 Pygmy Current Meter. Water temperature was maintained between 18 and $22^{\circ} \mathrm{C}$.

Insects were placed singly in the inner trough and water velocity increased until they appeared to be unable to make headway against the current. A total of 45 trials were run for each species. Trial results are given in Table 1.

\section{RESULTS AND DISCUSSION}

As predicted, insulata is best able to maintain its position against a current. But the ability of backswimmers to swim does not seem related to the mechanical advantage of swimming legs alone. Presumably, larger backswimmers have greater muscle volumes per unit of frictional surface, and as in Corixidae (Young 1969) swimming ability seems improved by large body size.

Notonecta insulata and irrorata are similar in body size but differ in hind-leg mechanical advantage and accordingly in swimming ability. The lower mechanical advantage of insulata favors its ability to swim against a current. Laboratory observations (Gittelman, in prep.) on the ability of these species to capture highly mobile prey (Corixidae) indicate that irrorata, presumably in part because of its higher mechanical advantage, is better able to make the short, quick attacks, necessary for capturing these prey.

When compared to irrorata and undulata, lunata has a low mechanical advantage. But due to its small size it swims only as well as irrorata. $N$. undulata is intermediate in body size and mechanical advantage and is intermediate in swimming ability. 


\section{ACKNOWLEDGMENTS}

I am particularly grateful to Tim Becker and John Parson for assistance in collecting data.

\section{Literature Cited}

Gittelman, S. H.

1974. Locomotion and predatory strategy in backswimmers (Hemiptera: Notonectidae). Am. Midl. Nat. 92:496-500.

Smith, J. M. and R. J. G. Savage

1956. Some locomotory adaptations in mammals. J. Linn. Soc. London Zool. 42:603-22.

Young, E. C.

1969. The swimming ability of Corixidae (Hem.). Entomol. Mo. Mag. 105:49-51. 


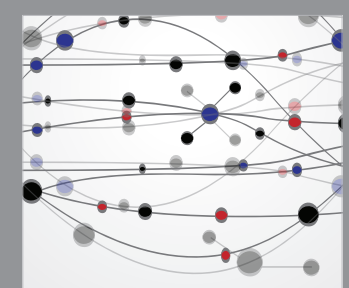

The Scientific World Journal
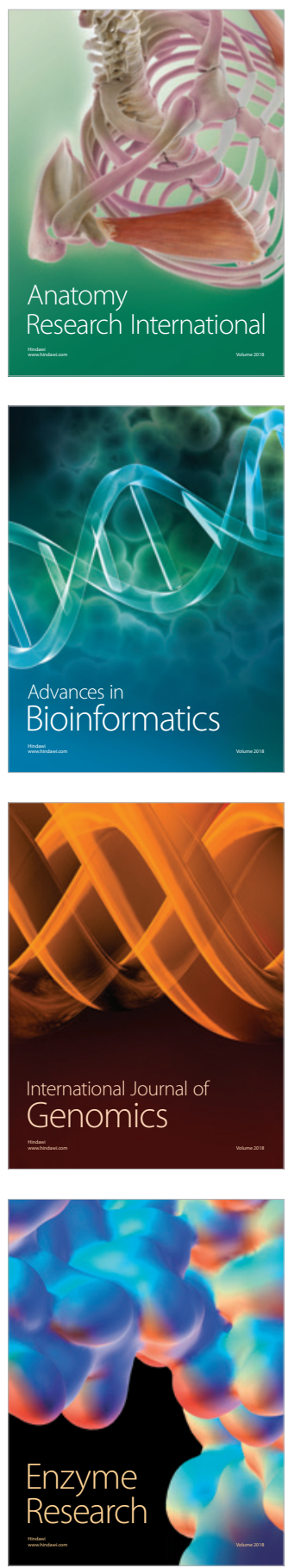
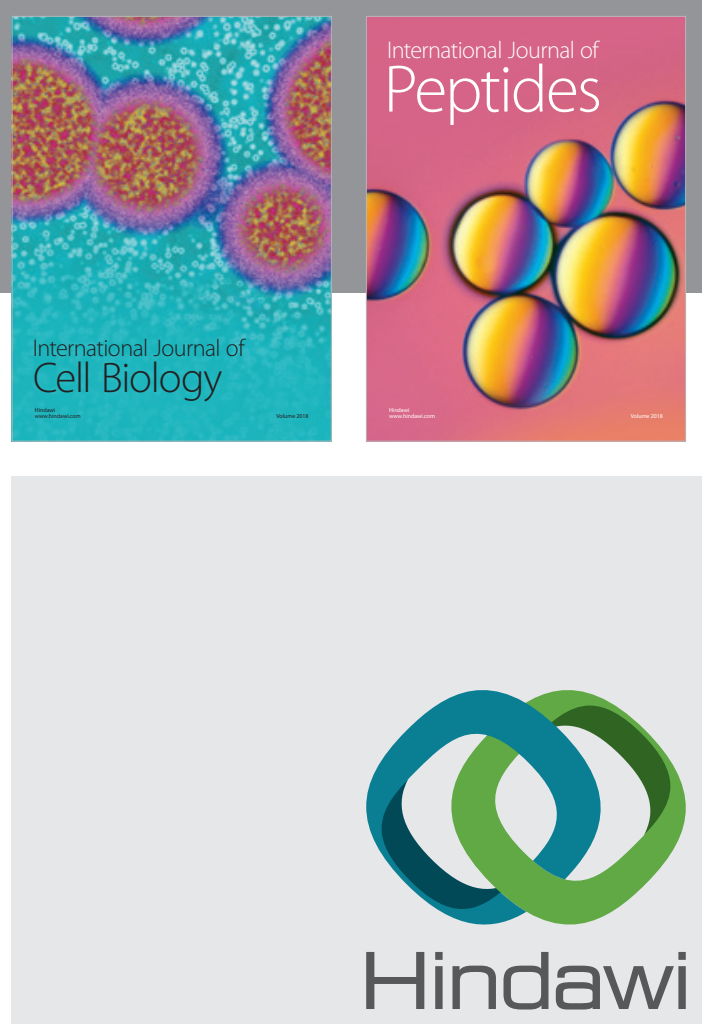

Submit your manuscripts at

www.hindawi.com
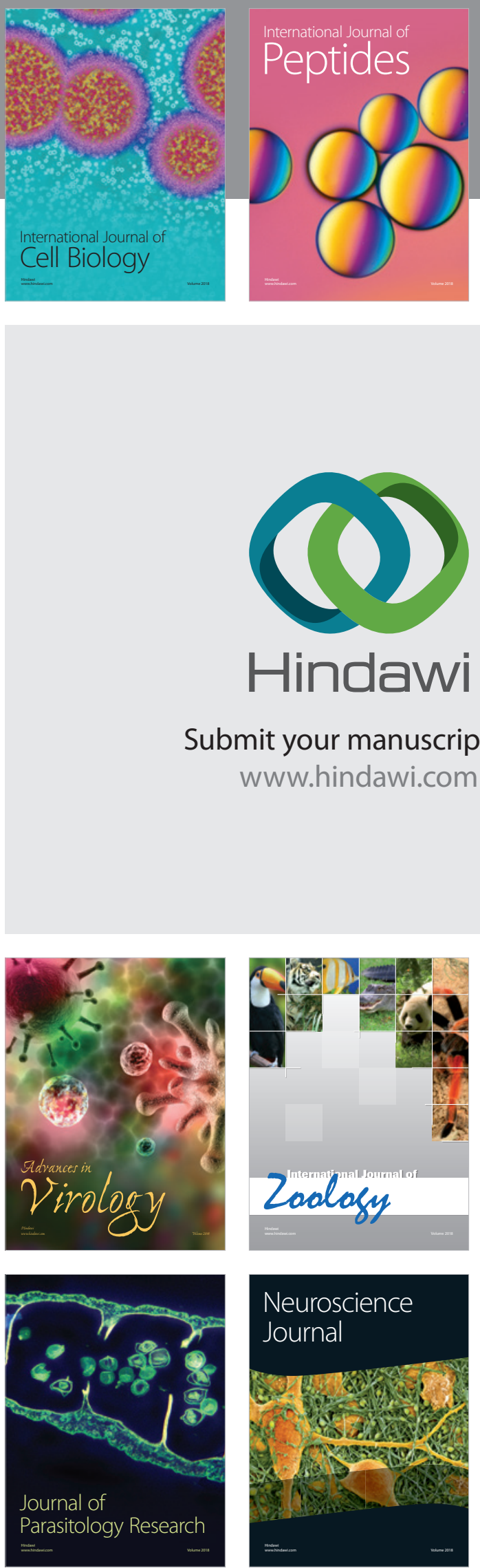
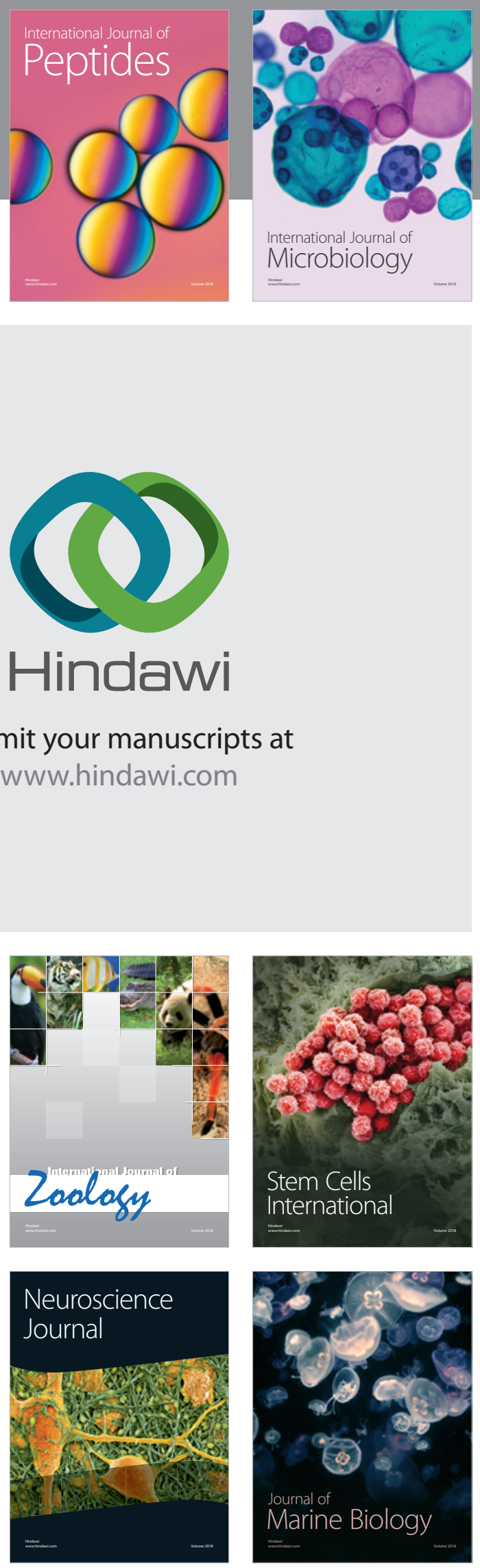
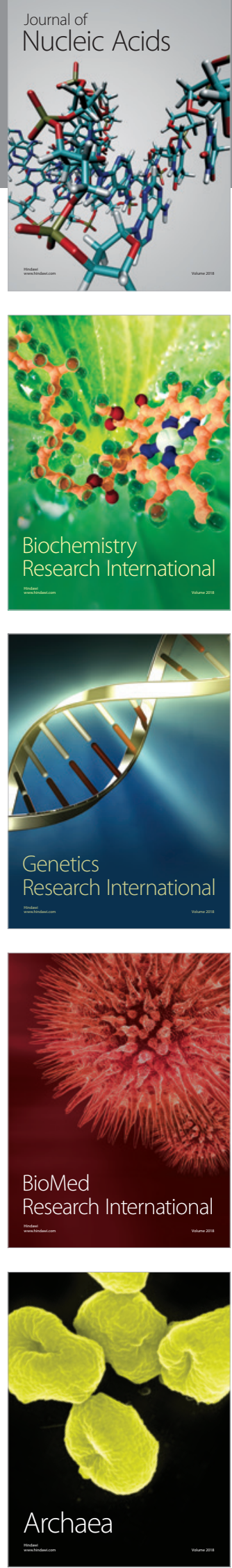